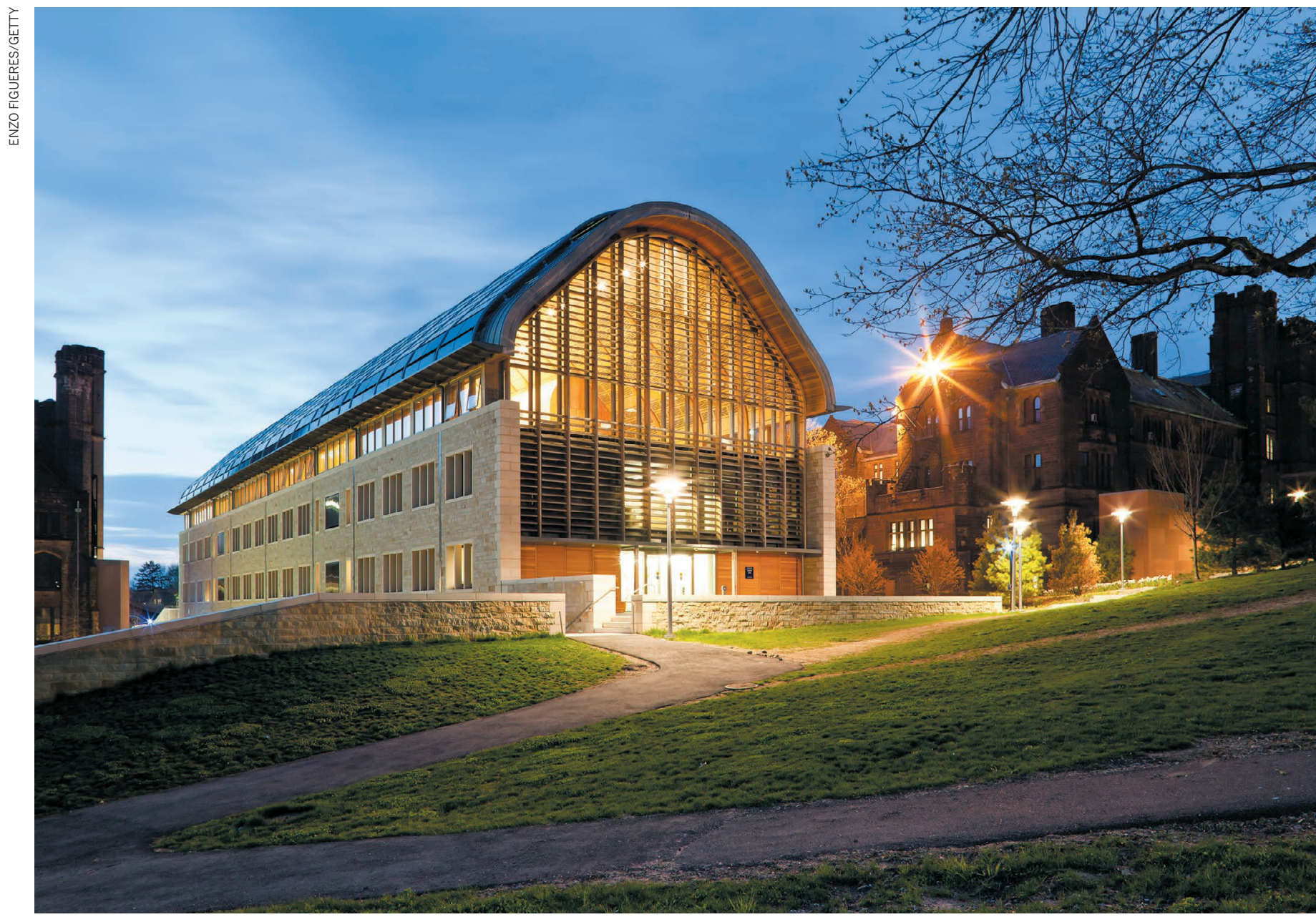

Kroon Hall, home to Yale University's environment school in New Haven, Connecticut, reduced emissions in the face of the carbon charge.

\title{
Lessons from first campus carbon-pricing scheme
}

\section{Putting a value on emissions can lower energy use, write Kenneth Gillingham, Stefano Carattini and Daniel Esty.}

I n July, Yale became the first university to launch a carbon-price programme across its campus. More than 250 buildings, together accounting for nearly $70 \%$ of the institution's emissions, will be charged US\$40 per tonne of carbon dioxide that they emit as a result of energy use. Buildings that reduce their emissions more than the average will receive a share of the funds collected.

More than 500 firms around the world three times more than a year ago - consider a carbon price of some kind when judging where to invest their money. Hundreds more are expected to start doing so in the coming months. Faced with higher prices, these organizations are shifting to energy uses that generate less emissions and are more efficient. Although some large companies have tried internal carbon pricing over the past two decades - BP was the first, in 1998 - little has been published about the value of such programmes. Here, we share initial insights and ideas for future research from a pilot scheme tried in 2015-16 at Yale - a prelude to the university's decision to roll out carbon pricing more broadly this year.

\section{PRICE SIGNALS}

Carbon pricing offers a direct incentive to reduce energy consumption and thus mitigate global climate change. In 2015, $13 \%$ of global greenhouse-gas emissions were subject to some form of carbon price, and this percentage is rising ${ }^{1}$, despite the challenges currently facing government-backed schemes (see 'National pricing').

A company or institution can implement a carbon price through an internal emissionstrading programme, a carbon charge or a 'proxy price' (or 'shadow price') on greenhouse-gas emissions.

In the first case, the firm caps its emissions at a given level for a fixed period and divides its allowances between its organizational units - in a similar way to the European Union Emissions Trading Scheme. Units then trade their allowances with each other. Buying allowances from units with lower 
pollution-reduction costs minimizes the overall cost to the company. BP used this approach to reduce its company emissions, quickly achieving its goal of a $10 \%$ cut from 1990 levels by 2010 (ref. 2).

An internal charge increases the price of carbon-intensive goods and services exchanged within the organization. The higher the price, the greater the incentive for the firm to decarbonize.

Companies can redistribute the revenue raised, or invest it in emissions-abatement schemes, as the luxury-goods conglomerate LVMH does. Ice-cream manufacturer Ben \& Jerry's invests its revenue in programmes to reduce emissions across its supply chain, on the basis of a "cow-to-cone" life-cycle analysis.

For the past five years, Microsoft has charged its business groups a carbon fee that appears quarterly in their profit-andloss statements. The fee covers energy consumption (adjusted for employee count) from data centres, offices and softwaredevelopment labs, as well as from business air travel $l^{3}$. The revenue raised goes towards buying renewable energy or improving the treatment of electronic waste or the energy efficiency of lighting, heating, ventilation and air-conditioning systems ${ }^{4}$. In 2015, this fee was about $\$ 4$ per tonne of $\mathrm{CO}_{2}$ (ref. 5); this is much less than the US government estimate of the 'social cost of carbon', which is $\$ 44$ per tonne. Low fees are common, with most internal carbon charges below $\$ 30$ per tonne of carbon dioxide.

\section{NATIONAL PRICING Faltering policies}

Governments are struggling to put an appropriate price on carbon dioxide. In 2016 , voters in the state of Washington rejected an initiative that would have set a tax on carbon emissions, despite broad support in polls for policy action on climate change. US President Donald Trump has backed away from the previous administration's Clean Power Plan. South Africa has delayed implementing a carbon tax. The United Kingdom has frozen its price floor for trading carbon at $£ 18$ (US\$24) per tonne of $\mathrm{CO}_{2}$ until 2021, rather than gradually raising it, as intended. According to the International Monetary Fund, most developed countries should price carbon at at least US $\$ 100$ per tonne of $\mathrm{CO}_{2}$ equivalent to reach their emissions-reduction targets for the 2015 Paris climate change agreement. The longer they wait, the higher these prices will need to be.

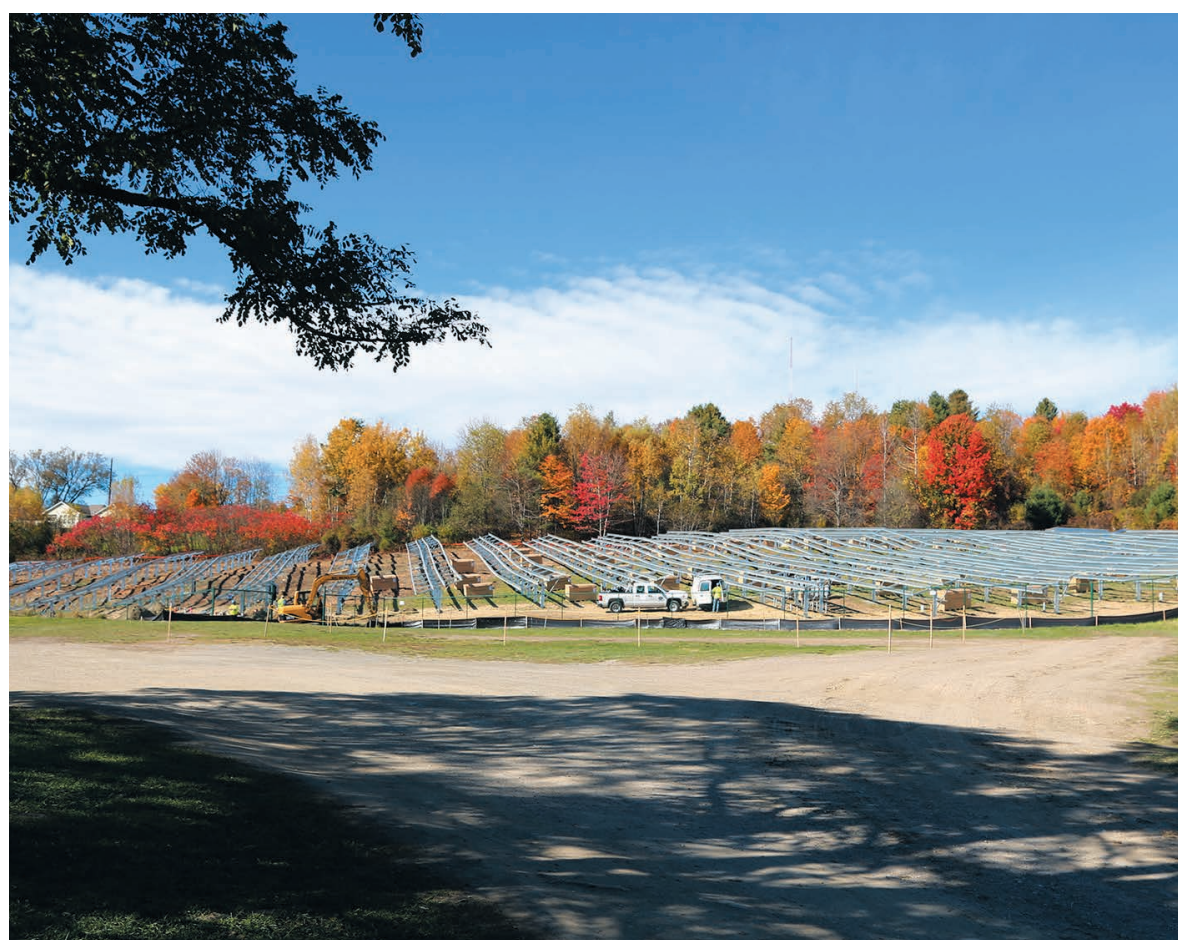

A solar-energy installation under construction next to the Ben \& Jerry's ice-cream factory in Vermont.

Proxy prices - which involve no financial transactions but are taken into account when weighing up business decisions - are often higher. No revenue is raised, but the carbon price shapes long-term investment choices. When deciding what sorts of buildings to construct or equipment to buy, the proxy price favours low-carbon solutions.

For example, ExxonMobil, the Texasbased oil-and-gas multinational, is using a proxy price of $\$ 10$ per tonne of $\mathrm{CO}_{2}$; that will rise to $\$ 80$ per tonne by 2040 (ref. 5). Proxy pricing drove Bristol Water, a British public utility company, to install more energy-efficient water pumps ${ }^{6}$. SaintGobain, a building-materials manufacturer based in Paris, uses a carbon price to drive investments in research and development for breakthrough technologies ${ }^{6}$. Some companies, such as the Dutch multinational Royal DSM in Heerlen, present two business cases for investments: one with and one without carbon pricing ${ }^{6}$.

\section{GETTING AHEAD}

Organizations are implementing internal carbon pricing for many reasons. By aligning investment decisions now, firms are preparing for more-stringent domestic climate policies and for future mandatory carbon pricing. They are also avoiding becoming locked into unprofitable investments and 'stranded assets', which are a concern for investors and others, and are preparing for changed future circumstances. For example, more than $80 \%$ of current coal reserves might need to remain untouched if countries are to limit warming to $2^{\circ} \mathrm{C}$ (ref. 7 ).
Committing to carbon pricing sends a signal to rating agencies and regulators that an enterprise is forward-looking and attentive to emerging climate risks ${ }^{8}$.

Internal carbon pricing is part of broader corporate or organizational social-responsibility efforts ${ }^{4}$. By using a carbon price rather than targets for renewable-energy procurement, or internal energy-efficiency standards, organizations achieve those goals in the most cost-effective way. Innovations may result from directing managerial attention to cheaper projects that improve operations or that reduce energy expenditure ${ }^{2}$. Managers do not need to know the exact costs of abatement to achieve progress.

Organizations can also pilot internal carbon-pricing schemes to shape future governmental decisions. Policy leadership was one of the motivations behind BP's internal carbon pricing 9 .

\section{LESSONS FROM YALE}

Yale University's carbon-charge pilot was launched as part of the university's broader sustainability initiative and ran from December 2015 to May 2016. The charges covered direct and indirect emissions from consuming energy sources such as electricity, gas, steam and chilled water. The price was set at $\$ 40$ per tonne of $\mathrm{CO}_{2}$, which was close to the US government's estimated social cost.

Each of the 20 buildings selected for the pilot received a monthly report that detailed energy consumption and carbon use. They were all randomly allocated to one of 
four approaches: no carbon price; carbon pricing with $20 \%$ of the revenue earmarked for energy-efficiency actions; pricing with the revenue redistributed to buildings that reduced their emissions by at least $1 \%$ relative to their historic level of emissions; and pricing with revenue that was returned to buildings whose percentage reduction in emissions exceeded the average. This last approach is revenue-neutral: a net charge applied if emissions reductions were below average, and a net rebate if cuts were above average. Campus buildings outside the scheme served as a control group. Emissions were estimated in proportion to the amount of energy used, with different factors for different sources.

By the end of the trial, buildings that had faced carbon charges had used less energy than those that had not (see 'Energy savings'). Reasons for this included increased awareness of energy use, competition between buildings and the higher price of energy.

Building managers were mainly responsible for responding to the charge. Some favoured cheap options, such as turning down the heat by $1^{\circ} \mathrm{C}$. Behavioural or operational changes, such as turning off lights and unused electrical equipment, also cost little. Others, including the departments of economics, environmental studies, public health and the boathouse, took more expensive measures such as installing occupancy sensors, thermal window shades or bulbs that use light-emitting diodes.

At the end of the pilot, the university selected the revenue-neutral pricing structure to implement campus-wide, because of its financial stability. The structure is not subject to potentially large outflows of funds if buildings exceed a target, saving energy because of an unusually mild winter, for example, or if energy needs rise unexpectedly owing to a cold snap or other reasons.

Of course, there are caveats. The scheme's novelty might have boosted engagement. Academics might be more interested than others in adopting challenging and original innovations. The sample size is small and the findings might not generalize to other situations.

Nonetheless, we feel that Yale's experience highlights important ingredients and challenges for internal carbon pricing.

First, information and incentives must be conveyed clearly for carbon charges to change behaviour.

After the pilot, more than half of the staff involved reported an improved understanding of energy use. The flow of information began with the energy reports to managers and spread through meetings with the staff and faculty, and through posters that explained energy savings. Students carried out energy audits. Actions were often

collectively identified and followed up by monthly e-mail updates.

Second, the details of the scheme matter. How energy information is presented and carbon-charge revenue is redistributed influence the effectiveness of the scheme. For example, exit surveys of managers indicated that they responded more to the 'net' carbon charge, calculated after they had received a rebate, than to the higher 'gross' charge. Thus, many perceived the price signal as smaller. To increase managers' response to the price signal, one of them suggested a "bump in pay" for good performance on the carbon charge.

Third, carbon pricing is more effective when participants consider the rules to be fair. Perceived fairness increases engagement and encourages competition. The baseline from which emissions reductions are compared is a crucial design factor because it influences winners and losers. Yale's carbon-pricing system recognizes that buildings vary in size, age and energy efficiency, and that research in some disciplines is more energy-intensive than in others. Emissions in the divinity school might be 100 times lower than those in the medical school, which hosts magnetic-resonance equipment. Hence, only emissions above the historic baseline count towards the carbon charge.

For the pilot, the average emissions in the previous three fiscal years, 2013-15, were used as the baseline. In the campus-

"Emissions in the divinity school might be 100 times lower than those in the medical school." wide scheme, fiscal years 2011-15 are being used, with adjustments for a few buildings with large renovations, additions, construction or directed growth. For example, emissions at Ezra Stiles College were exceptionally low in 2011-12 during a period of major renovation. Brand new buildings will require projections.

\section{FUTURE RESEARCH}

Four areas of research could improve the design of internal carbon-pricing schemes. First, scientists, engineers and economists need to identify and test design options using rigorous pilot projects, similar to Yale's. These should span organizations of many different sizes and complexities. Such tests would provide insights for policymakers.

Second, no evidence exists on how internal carbon charges interact with noncarbon-pricing policies, such as tax credits or other incentives for renewable energy or energy efficiency. Economists should explore these interactions through data analysis and natural experiments, such as from regulatory changes, including effects

\section{ENERGY SAVINGS}

Buildings that were charged for carbon emissions used less energy than did those that weren't in Yale University's pilot scheme.

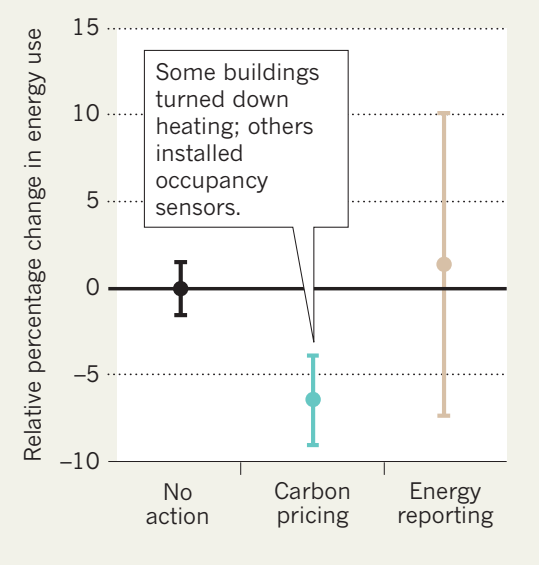

on consumers.

Third, building scientists and other metrics experts must develop methods to assure high-quality benchmarking and data analytics for emissions inventories and baseline calculations. Ideally, these metrics should cover a wide range of energy uses before an internal carbon price is set up.

Fourth, accounting and managerial expertise is required to define the tax and financial implications of internal carbon pricing, in particular for multinational and transnational organizations.

We are only beginning to understand internal carbon pricing, but it seems to hold great promise as a way to sharpen incentives and reduce greenhouse-gas emissions.

\section{Kenneth Gillingham is an associate} professor of economics, Stefano Carattini is a postdoctoral fellow and Daniel Esty is a professor of environmental law and policy at Yale University in New Haven, Connecticut. e-mail:kenneth.gillingham@yale.edu

1. Kossoy, A. et al. State and Trends of Carbon Pricing 2015 (World Bank, 2015)

2. Victor, D. G. \& House, J. C. Energy Policy 34, 2100-2112 (2006).

3. DiCaprio, T. The Microsoft Carbon Fee: Theory \& Practice (Microsoft, 2013).

4. DiCaprio, T. Making an Impact with Microsoft's Carbon Fee (Microsoft, 2015).

5. Carbon Disclosure Project. Putting a Price on Risk: Carbon Pricing in the Corporate World (Carbon Disclosure Project, 2015).

6. Carbon Disclosure Project. Embedding a Carbon Price into Business Strategy (CDP, 2016)

7. McGlade, C. \& Ekins, P. Nature 517, 187-190 (2015).

8. A group of the ESRB Advisory Scientific Committee. Too Late, Too Sudden: Transition to a Low-Carbon Economy and Systemic Risk. (European Systemic Risk Board, 2016).

9. Akhurst, M., Morgheim, J. \& Lewis, R. Energy Policy 31, 657-663 (2003).

Supplementary information accompanies this Comment online at go.nature.com/2zahe $2 q$. 